REVISTA ANDALUZA DE ANTROPOLOGÍA.

NÚMERO 3: MIGRACIONES EN LA GLOBALIZACIÓN.

SEPTIEMBRE DE 2012

ISSN 2174-6796

[pp. 228-236]

http://dx.doi.org/10.12795/RAA.2012.i03.11

\title{
SEGRE MALAGOLI, ENZO; MORENO NAVARRO, ISIDORO (coords.) (2012). Fronteras de iluminismo. México DF: UAM/Juan Pablos Editor, 266 pp.
}

\author{
David Lagunas \\ Universidad de Sevilla
}

El título de esta obra Fronteras de iluminismo es en sí la constatación de un problema no resuelto. Kant se pregunta en 1784 “QQué es el iluminismo?”, y la respuesta hoy- es motivo de múltiples controversias. El iluminismo, por definición, constituye la expresión cultural (científica, artística, filosófica, literaria, jurídica) del proceso de modernización (económica, militar, administrativa). Desde la crítica posmoderna, postestructuralista y poscolonialista de los 90, el iluminismo no solo se encuentra en retirada y en estado de asedio permanente sino fragmentado en múltiples pedazos. A pesar de ello, y paradójicamente, más recientemente han surgido nuevos enfoques que cuestionan la visión del iluminismo como imposible y equivocada, reivindicando su aporte original como movimiento de ideas tendente a pensar y construir una humanidad mejor, la defensa de un pensamiento radical, anticolonial y más libre, y la búsqueda de una verdad lógica desde la radicalidad de sus cuestionamientos en el dominio del conocimiento, no de la creencia.

En esta obra coordinada por Isidoro Moreno y Enzo Segreno no aparece una cronología ni una geografía exhaustiva de la Europa del siglo XVIII y los grandes hombres 
ilustrados. El objetivo es otro y consiste en aportar conocimiento, menos reduccionista y más exacto, de la complejidad del iluminismo y sus fronteras porosas y ambiguas desde diversos enfoques y perspectivas también fronterizas. Los diversos criticismos que aparecen en la obra dan cuenta tanto de la relación de los diversos textos entre sí y los ejes principales de las polémicas existentes como de la dificultad del consenso y las distancias ideológicas en torno al iluminismo, sobre todo respecto a su "herencia".

La posición de los autores atestigua cómo las promesas ilustradas optimistas de la fe en la ciencia y la razón, el progreso, el Estado-Nación, la separación entre lo público y lo privado, y, en general, la búsqueda del orden racional, no han llegado a cumplirse sino de manera parcial e imperfecta; pero sobre todo se constata que esas promesas se reproducen, se resignifican, se cuestionan y acaban conviviendo con otros grandes y pequeños relatos. Ello explica el porqué se sigue hablando del mito del progreso, el empirismo, el universalismo, el individualismo, la ciencia o la libertad. Los autores coinciden en que el progreso del orden racional no esta exento de contradicciones, tensiones y caos. La constatación de estos riesgos del movimiento de las ideas iluministas no es nada nuevo, de hecho, está contenida en los herederos de la ilustración, por ejemplo, Marx cuando señala "un espectro está rondando Europa", aventurando con ello el colapso del orden industrial burgués, racional.

A pesar de que la crítica convencional, por lo menos la de los sociólogos, considera al iluminismo como una herencia envenenada -el caso del nazismo como la tumba de la razón ilustrada-, ya Adorno y Horkheimer se cuidaron de advertir acerca de la naturaleza dialéctica del iluminismo, focalizándose en la crítica de la razón instrumental. Esta crítica temprana de los teóricos de la Escuela de Frankfurt es uno de los horizontes que planea en esta obra, esto es, la consideración del iluminismo como un proceso intrínsecamente dialéctico, que comprende elementos positivos y negativos.

Probablemente la naturaleza programática (y más combativa) de la obra se revela más claramente en los dos primeros textos de Eduardo Menéndez e Isidoro Moreno, a los que agregaríamos el de Alicia Castellanos.

Eduardo Menéndez plantea que nuestro modelo biogenético actual es un legado de la Ilustración europea y critica la "medicalización" de la sociedad como un efecto de un postulado iluminista capital: la verdad última es la verdad científica. Se trata de un modelo médico hegemónico que constituye la culminación de un proceso de institucionalización de la medicina, que aunque comienza en el siglo XIV, se expande fuertemente desde el siglo XIX y XX.

El enfoque de Menéndez muestra claramente la consideración dialéctica del iluminismo al ponderar la celebración posmoderna del fin de la racionalidad junto con la vigencia de los ideales ilustrados en el modelo biogenético. La propuesta de Menéndez se centra 
en el análisis en torno a qué categorías y propuestas del iluminismo, qué grandes y pequeños relatos, siguen vigentes. Ello le acerca al pensamiento de Dorinda Outram quien revela que no existe un proyecto iluminista unitario sino una "cápsula" de debates y preocupaciones que reflejan una diversidad de relatos y propuestas desde el siglo XVIII. Así pues, se enfatiza la heterogeneidad del iluminismo, sus tendencias contradictorias y diferentes tanto en la teoría como la práctica, pero asumiendo el potencial innegable del iluminismo para la reflexión sobre la libertad del individuo.

Para aprehender estos relatos Menéndez parte de la idea de que es imprescindible un enfoque teórico e ideológico que dé cuenta de los usos y apropiaciones de los actores en términos de las relaciones de hegemonía-subalternidad, identificando las continuidadesdiscontinuidades de las genealogías iluministas. Con ello pretende mostrar cómo los relatos del progreso científico, social y económico se reactualizan a través de los usos y coexisten con los relatos contemporáneos como la cuestión del "riesgo", a lo Ulrich Beck. En el "uso" reside entonces su propuesta teórico-metodológica, recuperando la dimensión ideológica y los criterios de verdad, en oposición a los seguidores de Foucault.

Isidoro Moreno plantea que la modernidad se define por el despliegue de las potencialidades de la razón, pero ello se desarrolla históricamente en el contexto de una sociedad europea que se presenta como modelo de civilización respecto a otras sociedades desde el siglo XIX. La consecuencia de ello es la naturalización del modelo occidental, el cual legitima el colonialismo. Moreno se recrea en la categoría "modernidad", tal como aparece definida en Durkheim (sociedad orgánica, evolución social), Tönnies (sociedad/comunidad) o Weber (proceso de racionalización), quienes dan cuenta de los ejes sobre los que se construyeron los modelos y las ideologías de la modernidad: el progreso (explotación de la naturaleza), la homogeneización cultural (aculturación, etnocidio, genocidio), la secularización (el desencantamiento del mundo) y el motor del cambio social (para los marxistas, la clase social, para la versión liberal, el individuo). Estos pilares de la modernidad -señala Moreno- han sido derrumbados y frente a quienes afirman la emergencia de una nueva era, Moreno se muestra escéptico y más partidario de la idea de que existe una continuidad entre modernidad, desarrollo, progreso y globalización.

Moreno argumenta que en tanto en cuanto no se ha producido un cuestionamiento al modelo económico y la lógica del mercado dominante, los mitos encuentran acomodo en la tríada del discurso ideológico de la globalización: los derechos humanos, el mercado libre y la democracia. De los derechos humanos, se cuestiona no solo que sirvan de pretextos para la dominación militar o económica sino que solo se atiendan los individuales, no los colectivos; sobre la democracia, los ciudadanos han sido convertidos en consumidores subalternos al mercado; y en relación al mercado libre, la situación se asemeja a la ley de la selva. Para Moreno este sistema y lógica de mercado se presenta 
como sacro e inevitable, y, lo más grave, como pensamiento único, siendo el efecto de un proceso de naturalización fundado en una razón universal, la occidental.

De manera mucho más diáfana, en el texto de Moreno aflora una consideración de que el proyecto iluminista ha sido responsable de una serie de patologías sociales, debido a que la fe ilustrada en la ciencia, el orden y el progreso ha sido sobrepasada y transformada en subyugaciones económicas, étnicas, religiosas, sexuales, políticas, subculturales. Todo ello simboliza, en mi opinión, la dificultad de asumir acríticamente el legado iluminista ubicándose en las ansiedades y tensiones generadas por la imposibilidad de la neutralidad (la idea del observador imparcial), el papel de la ideología, la desigualdad y la injusticia social. En suma, sobre el texto planea el problema del desorden frente a las categorías de pensamiento y la tradición ortodoxa basada en el pensamiento científico y el positivismo; ello también se conecta con la referencia de Menéndez al movimiento feminista como una parte central de la impugnación a la imposición de categorías ortodoxas sobre la totalidad social.

El texto de Moreno finaliza con un apartado más autorreferente respecto a las opciones que la antropología (y especialmente la antropología del sur) dispone para enfrentar el monofonismo del Norte, que no es sino una forma de tomar distancias respecto a los modelos y la lógica construida por el pensamiento iluminista; no cabe olvidar que los problemas que han sido el foco de atención de la reciente antropología social y las teorías para resolverlos fueron formulados en el periodo iluminista. Finalmente, propone dos reflexiones: una, sobre la necesidad de abatir la lógica racionalista-iluminista de que un problema tiene una sola solución (en base al criterio científico), recapitulando, en mi opinión, la propuesta de MacIntyre de substituir la racionalidad universal iluminista por "racionalidades". La otra reflexión incide en la fórmula de "pensar globalmente y actuar localmente", propia del modelo de las corporaciones empresariales, el cual debe ser substituido por el "pensar y actuar glocalmente".

Andrea Spini parte de la idea de trazar las fronteras del iluminismo siguiendo sus cortocircuitos y desde la epistemología de la relatividad propia de las ciencias sociales. Destaca cómo la autonomía del intelecto resulta ser la premisa básica del iluminismo, siendo ésta la respuesta kantiana a la pregunta “¿Qué es la ilustración?”: la salida del hombre de un estado de minoría. Uno de los cortocircuitos producidos por la razón iluminista es, precisamente, la propia ambigüedad de las categorías iluministas, que se traduce en sus efectos liberadores o de sometimiento. Con ello indica que la frontera, el limes de la ilustración, ya estaba trazado desde sus bases.

En esta línea, Spini señala que las nociones de razón y progreso fueron el paradigma ideológico del capitalismo, y repasa algunas claves en las ideas de Marx planteando que fue él mismo el que contribuyó a la legitimación de la vulgata evolucionistaprogresiva de su teoría económico-social, en sintonía con las leyes del desarrollo de 
Comte. No es de extrañar el soporte de Marx al colonialismo inglés sobre la India como una necesidad histórica de poner por encima a la razón como instrumento de liberación de las poblaciones "semibárbaras" y "semicivilizadas" como los hindúes, como si estos fueran cautivos de sus propios prejuicios. Ello justificaría la incorporación "dolorosa" de los "pueblos primitivos" al Progreso occidental.

El problema de fondo que plantea Marx es -según Spini- el del relativismo, lo cual se expresa en los dilemas actuales en los países del norte en relación a la acogida, respeto y reconocimiento de las minorías sociales y culturales provenientes del sur. Spini se recrea en cuestiones clave del momento actual como la incertidumbre, la inseguridad, el deseo de comunidad, el consumo, el individualismo, la búsqueda de la identidad, la cibercultura o la anomia generalizada. El autor está disuadido de que el estado líquido, a lo Bauman, y de dispersión, superficialidad e imposibilidad de una teoría crítica de la realidad, se expresa en el empleo habitual de metáforas y tropos en las ciencias sociales que escapan a la sistematización conceptual; ello resulta inconciliable con la lógica de cualquier “orden social". La conclusión de Spini es que nos encontramos definitivamente fuera de la razón iluminista e incorporados de pleno en la fase autodestructiva de la ilustración dominada por la razón instrumental, a lo que hay que sumar el fin del papel activo del intelectual sobre la sociedad, uno de los aspectos más definitorios del iluminismo.

Un síntoma de esta pérdida de referentes en la sociedad, y en específico el declive en las formas comunitarias y de autoorganización de la sociedad contemporánea, es para Spini los modelos de organización gerencial que invocan la organización social de los pigmeos como modelo para los trabajadores; se trata de recetas e instrucciones al uso que excitan a los ejecutivos empresariales, no de propuestas de reforma social. Frente a ello, se hace imprescindible un nuevo compromiso ético-político de amplio alcance.

En el texto que sigue, Enzo Segre analiza las contradicciones de nuestro tiempo dominado por la incerteza, la explosión brutal de los nacionalismos, la aceleración del tiempo y la contracción del espacio. De inicio, invoca el enfoque dialéctico de Adorno y Horkheimeren relación a que la razón es ambigua y se alimenta tanto de emociones como mitos. La dialéctica de Hegel también nos advierte que existen luces y sombras del iluminismo: por un lado, la razón instrumental produce la guerra, la manipulación ideológica, el totalitarismo (en términos goyescos "el delirio de la razón produce monstruos"); por el otro, la razón iluminista construye los principios éticos y políticos de la libertad y fraternidad humana.

A este respecto, y retomando la aptitud dialéctica positiva de Marx sobre la burguesía capitalista, Segre recuerda cómo la burguesía emplea la razón humanística para invocar la igualdad jurídica formal frente al antiguo régimen, pero muestra predilección por la razón instrumental para sus negocios. Este argumento es similar al texto de Alicia Castellanos quien se refiere a las ambigüedades entre los discursos de los ilustrados y sus prácticas en la vida real. 
Segre considera que el iluminismo es una revolución cultural y política, pasada por el tamiz de la razón y el pensamiento científico, la cual viene de lejos en la tradición occidental (el racionalismo filosófico griego). Por ese motivo, cabe contextualizar su supuesta universalidad. Por ejemplo, en América Latina el iluminismo fue adoptado por las élites dirigistas sin que estuviera conformada una sociedad civil, y fue parte consustancial de los proyectos de descolonización y construcción del Estado-Nación; paralelamente, el catolicismo oficial y popular, así como la penetración de las iglesias evangélicas en la región han evidenciado el fracaso de la modernidad en la región.

La respuesta de Kant a la pregunta sobre la ilustración ("la salida del hombre de su minoría de edad") tiene eco en la reflexión final de Segre en relación a las luchas contemporáneas por la emancipación, la construcción de las identidades colectivas y la descolonización. Estas luchas por la identidad corresponderían a la idea de emancipación de Kant, siendo el correlato del deseo concomitante de reestructurar la sociedad civil y política europea.

Obviamente, la cuestión de la religión es una de las prioridades de varios autores de esta obra, aunque no se retomen literalmente los cuestionamientos de los ilustrados acerca de la necesidad de creer. La religión es un concepto clave en el iluminismo; así, la religión cumple la función de racionalizar el medio, pero lo que la diferencia del discurso científico es que se propone como verdad inmutable, mientras la científica está sujeta a cambios y nuevas teorías. Desde Bruno Latour y su trabajo sobre los laboratorios científicos esta premisa ya no se sostiene ya que la ciencia también funciona como un sacerdocio que ejerce control social, como Menéndez plantea en su crítica al modelo médico.

Arnaldo Nesti aporta una perspectiva histórico-social para comprender los comportamientos religiosos en el seno del catolicismo italiano y sus relaciones con la sociedad. Desde la conversión de Constantino hasta el Concilio Vaticano II, el debate sobre la reforma religiosa sigue latente, y el conflicto entre laicidad y cristianización no ha sido resuelto. Nesti considera que el cristianismo se constituye como una religión civil y como sujeto político que ejerce un poder real confesional en la sociedad. Por ello, considera que la Iglesia, como depositaria de los valores identitarios, tiene la aspiración de convertirse en la posición cultural dominante, en alianza con las fuerzas laicas de la sociedad.

El argumento de Nesti deriva en una posición ideológica fuertemente discutible: como la razón humana (iluminista) no es capaz de fundamentar los valores y la moral de manera única, la fe en el Dios de los cristianos es la única vía para encontrar la verdad y el bien. Así, en el contexto actual de conjunción estrecha entre la vida político-social y la acción eclesiástica, por un lado, y la extensión del pluralismo religioso y la laicidad, por otro, la búsqueda del sentido de espiritualidad -entiende Nesti- es una tarea urgente. Nesti, sin embargo, obvia que el catolicismo de Juan Pablo II criticaba el iluminismo como responsable de los desastres y los totalitarismos del siglo XX. En la situación presente, 
no creemos que una Iglesia bunkerizada esté en condiciones de una alianza con otros sectores sociales, tal como plantea Nesti.

Pietro de Marco invoca la cultura católica y la tradición cristiana como patrimonio de Occidente y como la llave para la regeneración de las democracias europeas y la recomposición de las desarticulaciones de las instituciones occidentales. Basándose en el paradigma agustiniano de las dos civitates (civitates Dei y civitates hominum) plantea la complementariedad entre las dos, la divina y la social, entendiendo que lo sagrado y lo político se encuentran interrelacionados. De Marco no presta atención, por cuestiones metodológicas, a la importancia de la sociedad civil iluminista y la propuesta kantiana de asociación civil (civitas) intermedia entre el Estado y el individuo.Se centra, en cambio, en la "politicidad" particular de las religiones en el área euromediterránea de los siglos V-VI d. C (poderes romanos, cristianos, germánicos) como un modelo civilizador positivo y creativo, siendo la Modernidad desde el siglo XVI al XIX excéntrica y opuesta a este complejo civilizador católico-romano. Quizá uno de los pasajes más polémicos es su perplejidad ante el hecho de que el cristianismo no se mencione en las cartas constitucionales de la Unión Europea. De Marco considera que para la construcción de la Modernidad europea es imprescindible incorporar, conceptual y teóricamente, la "modernidad" de la Roma católica.

Los textos de Nesti y de Marcotoman partido en el debate acerca del escape o la legitimación de las tutelas religiosas. Quizás una de las ausencias en ambos textos es la referencia al papel de Rousseau, probablemente el primer contra-iluminista y responsable del giro seguido en el pensamiento occidental, vivificando y retornando filosóficamente al cristianismo desde un enfoque dialéctico que después continuarán el romanticismo, el existencialismo y el posmodernismo.

El último posicionamiento respecto a la cuestión religiosa aparece en el texto de Carlos Garma, quien se dedica a deconstruir el concepto de secularización. La secularización afirma- no es un fenómeno universal sino más bien europeo, y en concreto, propio de los países protestantes; de hecho, América Latina no se ha secularizado en su totalidad y el contacto con lo sagrado es una manifestación de larga duración en los ámbitos indígenas y rurales de México. Tampoco la secularización afecta del mismo modo a todas las instituciones y campos sociales, siendo el campo político aquel donde se extiende con mayor profundidad.

Garma distingue entre laicidad, como atributo específico de un Estado y sociedad donde lo religioso se ha acotado al ámbito privado, y secularización de la cultura, la cual se encuentra sujeta a procesos sociales en los que los símbolos religiosos, a la manera de Geertz, dan paso al manejo de otros símbolos para la construcción de los sentidos. Así, Garma destaca la fuerza de la religión y la expansión de sus fronteras en el hecho de la su presencia creciente como factor activo en el ámbito público, el manejo de símbolos 
católicos por parte de los políticos, el crecimiento del pluralismo religioso (conversión, herejías, New Age, etc.), la heterogeneidad de la creencia hacia lo sagrado, y el papel creciente de las instituciones y movimientos religiosos en la sociedad contemporánea. De la estrecha relación entre religión y política que enfatiza Garma, Marc Abélès había anticipado algunas pistas, tomando como ejemplo los viajes rituales del expresidente Mitterrand a la Francia periférica y profunda; tampoco es motivo de extrañeza por los argumentos aportados por Garma que en algunos países se plantee la educación para la ciudadanía inspirada por sacerdotes, signo de un regreso grosero de la religión.

Alicia Castellanos, en la línea crítica del pensamiento fronterizo de Walter Mignolo, reflexiona sobre las ambivalencias y el racismo de las Luces, la relación con la colonialidad y la creación de las jerarquías entre los pueblos, la intolerancia y el etnocentrismo, todos ellos anclados en las raíces científicas y filosóficas del iluminismo. Castellanos describe cómo el discurso iluminista está plagado de contradicciones y motivos racistas, constituyendo por ello la precondición del racismo moderno. De manera particular, explica cómo la apología del derecho natural en Locke contrasta con la teoría del determinismo climático, la degeneración de las razas o el esclavismo (el propio Locke invirtió en negocios de esclavos).La idea de la explotación de las clases y el racismo biologista y asimilacionista en el siglo XIX no sería entonces una reacción contra-iluminista sino que se encontraría incorporada en los escritos de Rousseau y Voltaire. Con ello, se revelan las incongruencias entre el discurso ilustrado de la razón, la igualdad y la ciencia, y el maltrato dispensado al Otro en el contexto de expansión colonial occidental.

Lo que revela el texto de Castellanos es que sencillamente no existe el buen colonizador en nombre de la difusión del progreso y la razón, como Locke (inversor en negocios de esclavos), Montesquieu (indiferente hacia la esclavitud), Voltaire (convencido de que la inteligencia de los negros era inferior), Condorcet (un racista paternalista que creía en la asimilación de africanos e indios) o Rousseau (admirador de los colonialistas holandeses). Lo que existe es "el colonizador". El buen colonizador es "el que no lo es". La crítica, implícita y explícita, al (neo)colonialismo y sus bases ilustradas se encuentra como tema recurrente en los textos de Menéndez, Moreno y Castellanos. Los modelos médicos hegemónicos y las lógicas de control de la natalidad en los países periféricos, la lógica sacralizada del mercado y la represión violenta institucionalizada o los prejuicios racistas de base iluminista implican transformar el mundo a nuestra imagen y semejanza. La crítica de Castellanos, al igual que en Menéndez y Moreno, comparte, en mi opinión, el rechazo al retrato vivificante del Siglo de las Luces y al de los grandes hombres, y se articula coherentemente con los procesos relacionados con el dominio histórico de los Estados-nación sobre las poblaciones nativas que son recluidas en reservas o bien diluidas en la población colonizadora, extranjerizadas, y mantenidas en su subordinación 
a través del etnocidio, genocidio y la violencia simbólica. A ello se suman, en la línea de la crítica de Spini al Marx "colonialista", las ideologías acusadoras que culpan a los pueblos dominados de su salvajismo, su pobreza y su incapacidad para incorporarse a la modernidad. Una modernidad, para Castellanos, "racializada".

El cierre del libro de Domenico Scafoglio sobre la comicidad del carnaval es un excelente ejercicio de ciencia descriptiva sobre la dimensión de la risa carnavalesca. Segre, en el prólogo ya nos advierte que este texto se sitúa en los márgenes de la obra. Ello crea cierta desorientación al lector que puede tener la sensación de leer un texto perteneciente a otro libro, desconectado con el resto de la obra en su conjunto. Aunque no aparece formulado con claridad cómo se inscribe su reflexión en el marco de la discusión teórica sobre el iluminismo, me atrevería a sugerir que la propuesta de Scafoglio se acerca al ideal ilustrado de la libertad humana, y a la vez, es cercana a las teorías de la represión en Habermas y sus críticas al iluminismo como un signo del dominio sobre una naturaleza externa objetivada y la represión de la naturaleza interna del ser humano. Esta naturaleza desinhibida y no-reprimida que encuentra Scafoglio en la comicidad, así como las contradicciones dialécticas de la figura del bufón (exceso-transgresión/ carencia-castigo), la cuestión del desorden integrado en el orden, la oposición naturaleza/ cultura, la génesis e imbricación con la diferencia interna y la diversidad étnica, son elementos que se relacionan con las fronteras del orden, tanto del pensamiento como la acción.

La conclusión que sigue de esta obra es que, a pesar de las consecuencias no previstas de los teoremas, las máximas, las deformaciones de las ontologías y epistemologías o los fracasos políticos, las fronteras del iluminismo siguen alimentándose de la reflexividad y la conciencia crítica como instrumentos que el propio iluminismo ha generado en su interior y que permiten reajustar continuamente los modelos. Por tanto, en el juego dialéctico, no solo cabe considerar los fracasos -ello sería una alienación- sino también los elementos positivos del pensamiento iluminista. La herencia del iluminismo, su actualidad misma, se asienta en su capacidad de generar un debate sobre el camino que los hombres deben realizar. El rostro de Janose hace presente, pasado y futuro del iluminismo. 